A Srivastava
RK Singh
S Varshney
P Gupta
SS Bist
S Bhagat
N Gupta

Department of ENT, Department of Microbiology, Himalayan Institute of Medical Sciences, Jolly grant, Doiwala, Dehradun

\section{Correspondence to}

Dr. Rakesh Kumar Singh, Associate

Professor, Department of ENT,

Himalayan Institute of Medical

Sciences, Swami Ram Nagar, Doiwala

Dehradun-248140.

E-mail: rksent5@gmail.com

\title{
Microbiological Evaluation of an Active Tubotympanic Type of Chronic Suppurative Otitis Media
}

Objective:

The purpose of this study was to isolate the organisms associated with a tubotympanic type of CSOM in a tertiary care centre and to detect the antibiogram of the isolates of the aerobic bacteria.

Materials \& methods:

One hundred and twelve aural swabs from the ears that were actively discharging of 110 patients were analysed from February 2008 to January 2009. Using pre-defined inclusion and exclusion criteria, the smears were obtained using sterile cotton microswabs, and cultured for microbial flora. Drug susceptibility testing was conducted using a modified Kirby Bauer disk diffusion method.

Results:

The most common causal organisms isolated were Staphylococcus aureus (29.2\%) followed by Pseudomonas aeruginosa (28.3\%) amongst the 106 bacterial isolates. Fungi accounted for $1.8 \%$ of the isolates while $3.5 \%$ were anaerobes. The antimicrobial profile of the major isolates i.e. Staphylococcus aureus and Pseudomonas revealed maximum sensitivity to cephalosporins ( $83 \%, 100 \%$ respectively) and to fluoroquinoles ( $76 \%, 97 \%$ respectively).

Conclusion:

Most of the isolates showed high sensitivity to cephalosporins and furoquinolones and at the same time high resistance to ampicillin and amoxicillin-clavulanic acid.

Keywords:

Antibiotics, chronic otitis media, microbiology.

\section{INTRODUCTION:}

Chronic suppurative otitis media (CSOM) has been a source of a tremendous health predicament since time immemorial and even today it is immensely intricate both for patients and an otologist to deal with. It is a chronic inflammation of the mucoperiosteum of the middle ear cleft which leads to abundant discharge from the ear and hearing impairment that may have a serious long-term effect on language, auditory and cognitive development and on educational progress. 1

In CSOM, bacteria can reach the middle ear from the nasopharynx through the Eustachian tube or from the external auditory canal via a perforated tympanic membrane. Various studies have shown that both gram positive and gram negative organisms are responsible for infection of middle ear, gram negative ones outnumbering the gram positive ones. The most common organisms associated with CSOM are Staphylococcus aureus and Pseudomonas. Others include Proteus, E. coli, Klebsiella, Enterobacter, non-fermenting gram negative bacteria and beta hemolytic Streptococcus. ${ }^{2}$

The role of anaerobes in CSOM is often questioned. They are mostly detected in cases with extensive cholesteatoma or granulation tissue. Fungal infection of the middle ear and meatus are common as fungi thrive well in moist pus. The most commonly seen fungi are Candida and Aspergillus. 3

The basic principles of the medical management of CSOM are aural hygiene and the use of a topical antimicrobial agent. The indiscriminate and haphazard use of antibiotics and poor follow-up of these patients has resulted in the emergence of multiple resistant strains of bacteria and the persistence of low-grade infections. 4

Knowledge of the prevailing flora and their susceptibility to antimicrobials will guide the clinician as to prescribing an empirical regimen so that a better and more specific management can be provided to the patients. Hence, this study is relevant in the present scenario. The purpose of this study was to isolate the organisms associated with CSOM and to detect the antibiogram of the aerobic isolates.

MATERIALS AND METHODS:

This prospective study was conducted in the Department of Otorhinolaryngology of a tertiary care centre in Uttrakhand over a period of 12 months from February 2008 to January 2009. One hundred and twelve (112) actively discharging ears of 110 patients afflicted with a tubotympanic type of CSOM were included in this study. The age of the patients ranged from six to 70 years old and the median age was 27.17 with a standard deviation of 16.88. The commonest age range of presentation was 11-20 and 21-30, consisting of 25 $(22.7 \%)$ cases in each category. Males outnumbered females (1.3:1). The disease was more prevalent in the lowest socio-economic group $(36.4 \%)$ of the patients under study.

Only those patients aged over six and showing an active tubotympanic type of CSOM diagnosed on the basis of an anamnesis of the current disease and an otoscopic examination were included in the study. Patients using topical or systemic antibiotics for more than a week were excluded. Moreover, patients with an inactive tubotympanic type of CSOM, CSOM with cholesteatoma, aural polyp or granulation, inflammatory external ear diseases, malignancy of the ear, an ear that had undergone surgery and those with debilitating diseases such as diabetes or immunosuppressive diseases were also not included in the study.

The external auditory canal of the discharging ear was cleaned by suction. Material for culture was obtained from the affected ear/s using thin sterile cotton wool micro-swabs with full aseptic precautions taken while using a microscope. Swabs were taken from the middle ear in the case of large and medium-sized perforations and from the surface of perforations when these were small. All the swabs were immediately processed in the Department of Microbiology by using Gram's stain and a KOH mount. They were cultured on Blood agar, MacConkey's and Chocolate agar for aerobic bacterial culture; and in Robertson's cooked meat media (RCM) / Thioglycolate media for anaerobic culture. Aerobic bacterial cultures were incubated at $37^{\circ} \mathrm{C}$ for 24 hours. The reading of the plate, colony identification and the recording of results were performed as per standard microbiological methods. 5

A subculture from RCM was cultivated on freshly prepared plates of blood agar and MacConkey's agar and the plates immediately put into a McIntosh Fildes jar with Gaspack for anaerobic incubation. The plates were examined after 48 hours of incubation. Fungal culture was performed on Sabouraud's dextrose agar as required. Anti-microbial sensitivity of aerobic bacteria was carried out using the Kirby Bauer Disc diffusion technique. The data thus obtained underwent standard statistical analysis. 
RESULTS:

From the 110 patients who had a tubotympanic type of CSOM, a total of 112 ear swabs were collected and sent to a laboratory so that the for the isolation of offending organism could be isolated and to evaluate the microbial sensitivity pattern against antibiotics.

Out of the 112 swabs, 22 (19.7\%) were sterile, while 90 (80.3\%) yielded growth of organisms and a total of 108 organisms were isolated. A total of 106 bacteria were cultured from 88 ears $(78.5 \%)$ while two $(1.8 \%)$ ears revealed fungal growth of Candida (Fig-1).

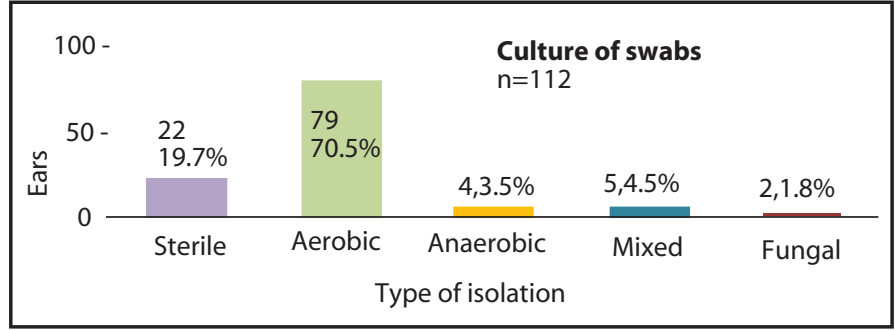

Fig: 1. Distribution of the groups of the organism in culture

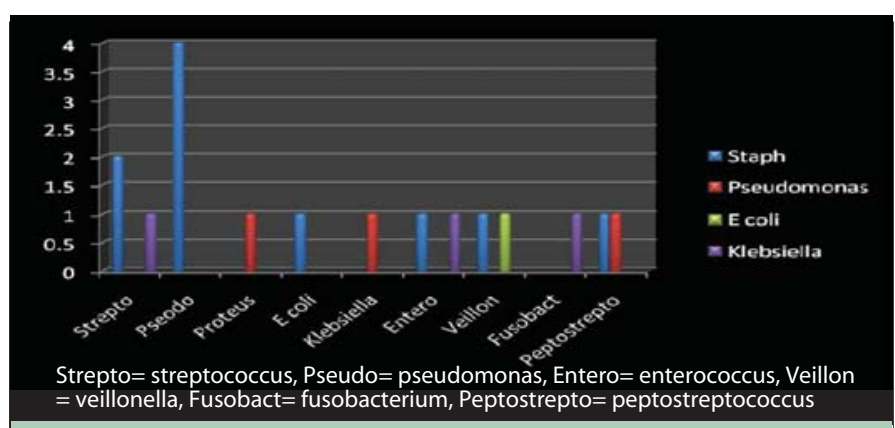

Fig: 2. Polymicrobial combinations of polymicrobial isolates

bacteria taken from the middle ear culture while material taken from 17 ears had two or more organisms isolated. Out of 17 polymicrobial growths, 16 cultures revealed a combination of two bacteria while one culture possessed three bacteria. The most common combination was that of Staphylococcus aureus with Pseudomonas species in four

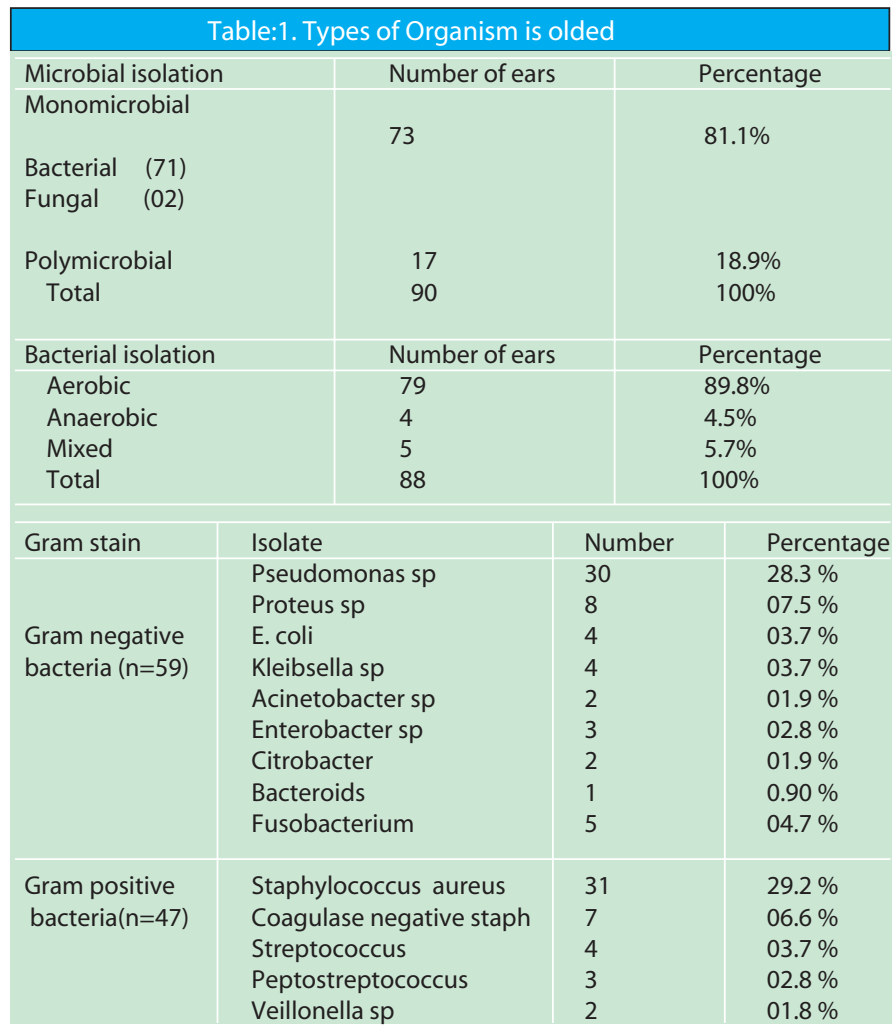

cultures (Fig- 2).

Amongst the 88 bacterial culture positive swabs, 79 were pure aerobic, Table: 2. Antibiotic profile of ogranisms

\begin{tabular}{|c|c|c|c|c|c|c|}
\hline Organism & Amp & Amox & Macro & Amino & Cepha & Fluoro \\
\hline Staphylococcus & $36 \%$ & $55 \%$ & $18 \%$ & $55 \%$ & $76 \%$ & $83 \%$ \\
\hline Streptococcus & $41 \%$ & $63 \%$ & $23 \%$ & $11 \%$ & $59 \%$ & $34 \%$ \\
\hline Pseudomonas & $23 \%$ & $15 \%$ & $22 \%$ & $60 \%$ & $97 \%$ & $100 \%$ \\
\hline Proteus & $17 \%$ & $19 \%$ & $34 \%$ & $67 \%$ & $86 \%$ & $90 \%$ \\
\hline
\end{tabular}

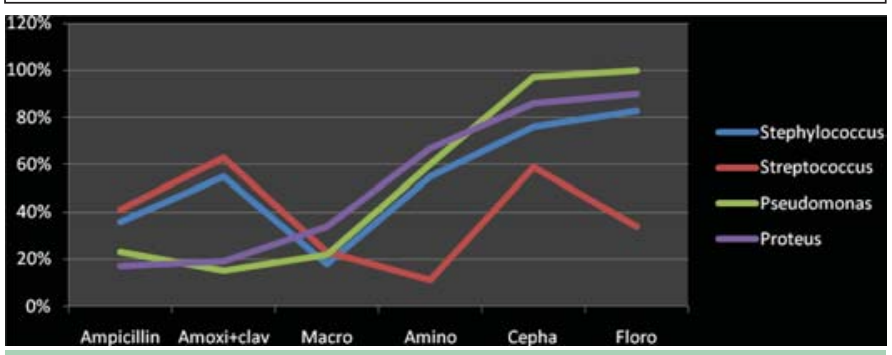

Fig: 3. Sensitivity patterns of major bacteria isolated

four pure anaerobic while five swabs revealed a mixed aerobic and anaerobic growth. Out of 106 bacteria isolated after culture, the majority were gram negative $(59,55.6 \%)$ as compared to gram positive bacteria $(47,44.4 \%)$. Pseudomonas $(30,28.30 \%$ ) were the commonest bacteria isolated in the gram negative group followed by Proteus in eight cases and E. coli in four cases. However, Staphylococcus (31, $29.24 \%$ ) outnumbered the other organisms as a whole and in the gram positive group (Table -1).

The antimicrobial profile of the microorganisms tested revealed that both for gram positive and gram-negative organisms, cephalosporins and fluroquinoles showed maximum sensitivity with $(83 \%, 76 \%)$ and (100\%, 97\%) sensitivity for Staphylococcus and Pseudomonas respectively (Table -2 , Fig-3).

DISCUSSION:

In the present study the age groups with the highest percentage of presentation of these problems were 11-20 and 21-30 years, there being $25(22.7 \%)$ cases in each of these age ranges. These findings were consistent with the findings of Shreshtha \& Sinha6 and Singh \& Safaya7. The basis for delayed presentation may be due to the ignorance of and/or the economic restraints on the patients with regard to their seeking health services at an early stage of the complaint.

CSOM was more common in males (56.3\%) as compared to females (43.7\%). An analogous conclusion has been made by other researchers such as Chandra \& Mishra8, Mukherjee et al9 and Hossain et al. 10 The predominant cause of the disease in males was due to their outdoor working habits exposing them to contamination and contagion.

In our study no growth was seen in 22 swabs (19.7\%) while 90 (80.3\%) swabs were positive for the growth of microorganisms. Similar studies by Gulati \& Kumar11 showed $22 \%$ cases with no growth and Nikakhlagh et al 12 reported no microbial growth in $18 \%$ cases. The low positivity rate in our study could be because of the fact that our hospital is a tertiary care centre. Patients usually come to us after having sought medical advice from local doctors and having taken multiple or incomplete course of antibiotics. It may also be because they have not revealed to us the prior administration/ instillation of antibiotics that could have hampered microbial growth in these cases. Secondly, certain organisms like Mycoplasma and Chlamydia are difficult to grow using routine culture methods and may have been missed in the present study.

In our study, out of 88 bacterial cultures, multiple microorganisms were isolated in 17 (19.3\%) swabs while, a single bacterium was present in $71(80.7 \%)$. Amongst the polybacterial culture, two organisms were isolated in 16 cultures with the most common being of Staphylococcus with Pseudomonas. The combination of Pseudomonas with Fusobacterium and Peptostreptococcus was seen in one swab. Poorey 
\& lyer13 and Kumar et al 14 also showed a lesser number of mixed isolates. A lesser number of polymicrobial isolates could perhaps be due to the changing pattern of the process of the disease, the increasing trend of using combined antimicrobials and some other unidentified factors that needs to be sought out by further research.

Amongst the 106 micro-organisms identified on a bacterial culture, the commonest isolate was Staphylococcus aureus, this appearing in 31 (29.24\%) ears. A Similar number of isolates has been reported by Kukreja et al 15 (33.9\%), Freidmann study 16 (32.7\%), Nikakhlagh et al 12 (32.4\%) and Ettehad et al17 (31.1\%). Staphylococcus aureus as the commonest pathogen was also observed by Pajor et al 18 , and Ayson et al19 in their respective studies. These authors give an explanation of how the close relationship between the auditory tube and the upper tract is related to the high incidence of Staphylococcus aureus.

In second place after Staphyloccus aureus was Pseudomonas in 30 ears (28.30\%). It was also isolated as one of the predominant organisms by Bairy et al20, Poorey \& Iyer ${ }^{13}$, Maji et al21, Kumar et al14 and Indudharan et al.22 The occurrence of Pseudomonas aeruginosa as the prime offender can be attributed to various factors. Pseudomonas, survives competition with other pathogens due to its minima nutritional requirement and its armamentarium of antibacteria products, pyocyanin and bacteriocin. Vartiainen \& Vartiainen 18 postulated that Pseudomonas has the ability to carve out a niche for itself in local infection through the necrotizing activities of its extracellular enzymes. The physical characteristics of the niche, a damaged epithelium, interrupted circulation and devitalized tissue protects the organism from normal host defence mechanisms and antibiotic agents. In addition, the organism acts as an opportunistic pathogen, flourishes in the external auditory canal and may cause suppurative disease in contiguous sites.

Anaerobic bacteria were not a significant pathogen in the present study. Pure anaerobic isolation was almost negligible and only seen in four (4.5\%) ears. Mixed growth with aerobes was observed in five (5.7\%) ears. The most common anaerobic organism isolated was Fusobacterium followed by Bacteroids and Peptostreptococcus. Ibekwe et al3, Maji et al21 and Indudharan et al22 also found negligible anaerobic isolation. The lower isolation rate can be attributed to the fact that anaerobes are usually associated with cholesteatoma and granulation tissue and our study was on a tubotympanic variety of CSOM.

In our study, the sensitivity of Staphylococcus aureus to ampicillin, amoxycillin-clavulanic acid, macrolides, aminoglycosides, cephalosporins and fluroquinolones were $36 \%, 55 \%, 18 \%, 55 \%, 76 \%$ and $83 \%$ respectively. This was in accordance with studies by Maji et al21 and Bairy et al.20

The microbial sensitivity of Pseudomonas revealed that all the isolates were sensitive to fluroquinolones, while, $97 \%$ were sensitive to the cephalosporin group and $60 \%$ to aminoglycosides. Only 23\%, 22\% and $15 \%$ were sensitive to ampicillin, macrolides and amoxicillinclavulanic acid respectively. Similar data were obtained by Indudharan et al22 Loy et al24 and Ettehad et al.17 Bairy et al 20 concluded that ampicillin (1.5\%) and amoxicillin-clavulanic acid (6.3\%) were the least effective antibiotics. Data from Ayson et al 19 study showed only $35.7 \%$ sensitivity to penicillins while $85.7 \%$ were sensitive to Fluroquinolones and $83.3 \%$ were sensitive to amikacin.

However, some results have shown a much lower sensitivity pattern for fluoroquinolones. Kumar et al 14 reported only $63.2 \%$ sensitivity for ofloxacin and $59.6 \%$ sensitivity for ciprofloxacin. Similarly, Maji et al21 showed a $46.6 \%$ sensitivity rate of ciprofloxacin. The decreased sensitivity of Pseudomonas to the quinolone family, to which it was highly sensitive until recently, is indicative of the rapid appearance of antibiotic resistant strains of Pseudomonas which is a matter of great concern.

Other isolates in the present study also showed high sensitivity to cephalosporins and fluoroquinolones while displaying a high resistance to ampicillin and amoxicillin-clavulanic acid. Thus it can be aptly said that the strains that were sensitive to commonly used drugs like ampicillin, amoxicillin have developed resistance but have retained sensitivity to quinolones, cephalosporins and aminoglycosides.

\section{CONCLUSION:}

The result of the present study and its similarity with the number of recent published articles clearly indicate high resistance to primitive antimicrobials. This might have been due to the widespread and injudicious use of primitive antimicrobials which has led to their having been rendered ineffective. The patients belonging to the lowest socioeconomic group for whom health care facilities are greatly lacking in resources avail themselves of indigenous methods or consult unqualified medical practitioners, who recommend they take the more commonly available and cheaper antibiotics of an earlier generation but who do not carry out antibiotic sensitivity tests. These factors further increase the chances of the microorganisms being resistant to such antibiotics. However, the new generation of antibiotics have shown an outstanding sensitivity pattern as exemplified both in the published literature and in the present study. Thus judicious use of antibiotics following antibiotic sensitivity tests should be standard practice so as to limit the emergence of drug resistant isolates and to provide an appropriate clinical response.

\section{REFERENCES:}

1. Healy GB, Rosbe KW. Otitis media and middle ear effusions. In: Snow, Ballenger JJ, editors. Ballenger's Otorhinolaryngology Head Neck Surgery. (16th ed). BC Decker Inc; 2003: 249-60.

2. Varshney S, Gupta P. Bacteriological study of chronic suppurative otitis media. Indian J Otol 1999; 5: 87-91.

3. lbekwe AO, al Shareef Z, Benayam A. Anaerobes and fungi in chronic suppurative otitis media. Ann Otol Rhino Laryngol 1997; 106: 649-52.

4. Holmberg SD, Solomon SL, Blake PA. Health and economic impacts of antimicrobial resistance. Rev Infect Dis 1987; 9: 1065-78.

5. Collee JG, Miles RS, Watt B. Tests for the identification of bacteria. In: Colllee JG, Fraser AG, Marmion BP, Simmons A, editors. Mackie and Mc Cartney, Practical Medical Microbiology. (4th ed). London: Churchill Livingston; 1996: 131-50.

6. Shreshtha S, Sinha BK. Hearing results after myringoplasty. Kathmandu Univ Med J 2006; 4: 455-9.

7. Singh RK, Safaya A. Middle ear hearing restoration using autologous cartilage graft in canal wall down mastoidectomy. Indian J Otol 2005; 11: 10-4.

8. Chandra R, Mishra RN. Some Observations on the total and subtotal perforations of the tympanic membranes. Indian J Otolaryngol 1964; 16: 3-20.

9. Mukherjee P, Saunders N, Liu R, Fagan P. Long term outcome of modified radical mastoidectomy. J Laryngol Otol 2004; 118: 612-6.

10. Hossain MM, Kundu SC, Haque MR, Shamsuzzaman AK, Khan MK, Halder KK. Extracranial complications of chronic suppurative otitis media. Mymensingh Med J 2006; 15: 4-9.

11. Gulati SK. Investigative profile in patients of chronic suppurative otitis media. Indian J Otol 1997; 3: 59-62.

12. Nikakhlagh S, Khosravi AD, Fazlipour A, Safarzadeh M, Rashidi N. Microbiologic findings in patients with chronic suppurative otitis media. J Med Sci 2008; 8: 503-6.

13. Poorey VK, lyer A. Study of bacterial flora in CSOM and its clinical significance. Indian J Otolaryngol Head Neck Surg 2002; 54:91-5.

14. Kumar S, Sharma R, Saxena AK, Pandey A, Gautam P, Jain R. A study of bacterial flora and sensitivity to antibiotics in cases of CSOM TTD in western UP. Indian J Otol 2008; 14: 20-4.

15. Kukreja SM, Kohli GS, Mohan C, Chanda R. Microbiological study in chronic suppurative otitis media. Ind Med Gazette 1979; 3: 95-8.

16. Freidmann I. Bacteriological studies in otitis media. J Laryngol Otol 1952; 66: 175-80.

17. Ettehad G, Refani S, Nemmati A, Pirzadeh A, Daryani A. Microbial and antimicrobial susceptibility patterns from patients with chronic otitis media in Ardebil. Int J Tropi Med 2006; 1: 62-5.

18. Pajor A, Durko M, Jankowski A, Bartoszko TA, Stanczyk R. Bacteriological evaluation in chronic otitis media. Otolaryngol Pol 2006; 60: 757-63.

19. Ayson AN, Lopez JEG, Llanes EGD. Chronic suppurative otitis media: Bacteriology and drug sensitivity patterns at the Quirino memorial medical centre (2004-05): a preliminary study. Philippine J Otolaryngol Head Neck Surg 2006; 21: 20-3.

20. Bairy I, Pradhan D, Yenigalla BM. Microbiology of chronic suppurative otitis media. Indian J Otol 2007: 13: 21-4.

21. Maji PK, Chatterjee TK, Chatterjee S, Chakrabarty J, Mukhopadhyay $\mathrm{BB}$. The investigation of bacteriology of chronic suppurative otitis media in patients attending a tertiary care hospital with special emphasis on seasonal variation. Indian J Otolaryngol Head Neck Surg 2007; 59: 128-31.

22. Indudharan R, Haq JA, Aiyar S. Antibiotics in chronic suppurative otitis media: a bacteriologic study. Ann Otol Rhinol Laryngol 1999; 108: 440-5.

23. Vartiainen $E$, Vartianen J. Effect of aerobic bacteriology on the clinical presentation and treatment results of chronic suppurative otitis media. J Laryngol Otol 1996; 110: 315-8.

24. Loy AH, Tan AL, Lu PKS. Microbiology of chronic suppurative otitis media in Singapore. Singapore Med J 2002; 43: 296-9. 